\title{
The Application of the Mind mapping to the Autonomous Learning of Higher Vocational Students
}

\author{
Cuijun MU \\ Hebei College of Industry and Technology, \\ Shijiazhuang,Hebei,050000 China
}

\author{
Lei Zhang \\ Hebei education propaganda center
}

\author{
Yong Zuo \\ Hebei University, \\ baoding,071002 China \\ Chao Li \\ Hebei University, \\ baoding,071002 China

\section{Jinling Si} \\ Hebei College of Industry and Technology, \\ Shijiazhuang,Hebei,050000 China
}

\begin{abstract}
Mind mapping is a way of expressing divergent thinking, which can organize information through pictures, colors, texts, lines and other forms and is oriented at a radioactive structure in order to strengthen the mind and improve the learning efficiency. In this paper, mind mapping is integrated into the autonomous learning of higher vocational students according to these students, so that mind mapping becomes an effective autonomous learning tool and also improves the autonomous learning effect and level of the students.
\end{abstract}

\section{Keywords: Mind Mapping; Autonomous Learning}

\section{Introduction}

Along with the increasingly rapid development of science and technology and knowledge economy, mind mapping has attracted the wide attention of the world, because it is a good tool of thinking. With the application of mind mapping, the ability of people in collecting and processing data and analyzing and solving problems can be improved, and also people can be helped to effectively enhance memory, organizing ability and creativity. For higher vocational students, they can improve the ability in autonomous learning if mind mapping is well applied.

\section{Mind mapping and use}

Mind mapping is an expression to divergent thinking, but also a natural function of human mind. Mind mapping can enhance the memorizing effect using color, graphics, and text-image combined forms, so that it looks more interesting and characteristic, and promotes people to focus on clearly the central graphics and lets students produce unlimited association. As a result, the process of thinking is more creative. For higher vocational students, this way of expressing thinking is not difficult to study, and they only need to grasp several elements of mind mapping.

First, it is necessary to know well graphics. Mind mapping is graphics essentially, which can play the full potential of mind mapping. Graphics can be equal to thousands of words and promote people to fully imagine and combine unfamiliar things with familiar things together. It can not only stimulate the creative thinking, but also can strengthen memory. Thus, the parts of mind mapping, such as central image and key images in branches, can be expressed with graphics rather than words if possible. Moreover, graphics is more conductive to let people concentrated and associate if it is vivid and interesting.

Second, it is necessary to know well key words. The memory subjects of people often are 
some simple key words, and people will think of some related experience and feelings once they see these words. Meanwhile, these simple key words will let mind mapping look more clear and marked.

Third, it is necessary to pay attention to branches. Mind mapping is a radioactive structure, which fits the divergent thinking of people. It is composed of many branches extending from the center, and each branch is a set of contents related to the center, including keywords or formatively cute icons.

Finally, it is necessary to focus on color. A significant difference of mind mapping from the graphic information of other traditions lies in that mind mapping can extremely stimulate the brain through the use of colors and enhance memory and creativity. On the contrary, color can add leaping feeling and vitality into mind mapping and creative thinking.

\section{The learning characteristics of higher vocational students}

First, seen from learning interest and motivation, higher vocational students have a low competence generally even if they possess certain ability in autonomic learning, because of complex admission source and different learning foundation. They are easy to become emotional in the learning process, and will take great initiative to what they are interested in, and otherwise the momentum is obviously inadequate.

Secondly, higher vocational students are obviously oriented at real professions in terms of learning methods. At the beginning of entering to higher vocational colleges, these students have gotten a basic understanding of jobs in the future and will learn basic courses and major courses around a professional orientation. However, many students still continue to use the middle-school learning methods in the process of learning, and can't skillfully summarize and improve what they have learned and also excessively rely on teachers.
Third, in terms of learning autonomy, the environment for higher vocational students is much looser and they have more time to control learning freely in comparison with the learning during the period of middle-school learning. Therefore, learning channels for them are diversified and learning resources are more abundant, and learning contents are selective, promoting autonomous learning to be more easily implemented.

Fourth, in terms of self-control ability, many students play mobile phone or read an occasional book in class, and some students even are absent in class and exams. All these realities show that the self-control ability and self-monitoring consciousness of higher vocational students are weak, and these problems will give rise to many troubles in the cultivation of students' autonomous learning ability.

\section{The application of mind mapping to higher vocational students' learning}

Teachers can ask students to make their own learning plans and goals ahead of time using mind mapping, and promote them to plan their own learning process and carry on the inquiry learning. Meanwhile, mind mapping can become a learning evaluation tool for the sake of the consolidation and review of the knowledge.

\subsection{Making learning plan and goal using mind mapping}

Without advanced planning and preparation, victory is not easy to win. Before learning, making a self-plan and goal can directly influence the learning effect. Some students, in the process of making goals, are blind and can't catch the points. Using mind mapping as a tool, students can straighten out the train of thought, clearly find their goals, mark the learning contents and related questions with icons, and joint the learnt with the unlearnt together within a short time, so that their learning can be done in a targeted way, the learning efficiency is 
improved, and the learning process is more scientific and systematic.

\subsection{Recording notes with mind mapping in the classroom}

In class, many higher vocational students have been used to listening to teachers and keeping what teachers speak on notes, and they do not have their own ideas and thoughts in the whole class. Some students do not keep notes and their minds are not concentrated on class even if there are in the classroom. In view of this situation, the attention of students can be effectively attracted if they write and take notes using mind mapping. In the process of teaching, students can take notes according to their own understanding through mind mapping, and replace a large amount of language information with a small number of words, keywords or key images for the sake of easy memory.

\subsection{Making learning evaluation with mind mapping}

Students can evaluate their own learning results with mind mapping. For example, students can know well their own learning situation, grasp the process of learning, and timely adjust and improve the existing problems by constructing their own mind mapping. In addition, students can make a summative evaluation using mind mapping and help them reconstruct a knowledge structure for promoting them to seize the knowledge systems from the whole and macro level, and thus, they can get a good selfrecognition on their own learning.

\subsection{Consolidating knowledge using mind mapping}

Mind mapping, relying on a good constructive knowledge framework, can connect all sorts of knowledge radiated from the center through key words and lines - connect knowledge blocks as a knowledge network and help students consolidate and integrate the knowledge, and thus, the chaotic pile-up of knowledge in the brain is prevented. Specifically, students can choose the most satisfied mind mapping in each class in the process of learning: a small figure is established for each lesson, and a big figure is set for each chapter. That is to say, scattered knowledge is used as a branch figure and summarized into the general figure of each chapter, and thus, new knowledge can be added into the existing knowledge system in a timely manner, the knowledge points and contexts of an entire book can be better controlled, the link between the knowledge points can be known well. Ultimately, students can form their own unique knowledge network in the process of knowledge construction, so as to consolidate and classify the knowledge. In addition, in the process of reviewing, mind mapping has its own unique advantages. In other words, students can draw up a map using their favorite color, lines and graphic design in the production process, which looks bright and easy to remember.

\section{The mind mapping application advantages in the autonomous learning of higher vocational students}

First, students can be helped to systemically understand the knowledge if mind mapping is introduced to the autonomous learning of higher vocational students. Based on the characteristics of mind mapping and divergent structure, the information contained within it is more distinct in layers and more effective in recording the knowledge structure. Thus, it is more helpful for students to grasp the knowledge framework from the macro level.

Second, the application of mind mapping to learning can help improve the students' interest in learning and enhance their comprehensive quality. Compared with the previous traditional way of learning, students can play a dominant role in the process of applying mind mapping to learning, and also their goals are explicit so that they can autonomously construct a knowledge framework under the guidance of teachers. The whole process can greatly exert students' initiative, arouse students' interest in learning, and improve the internal motivation. The construction of mind mapping can also make 
their self-confidence enhanced, and the sense of honor is fully fulfilled.

Third, mind mapping plays a positive role in promoting students to cultivate a complete thinking way. Mind mapping provides a thinking "panorama" and can promote the thinking of people to start from focus issues and indefinitely spread and extend from different branches. As a result, students are inspired to create creative thinking and innovative solutions. The process of students to draw a mind map is a reprocessing of old and new knowledge. Students, as the main body of learning, unceasingly integrate new knowledge based on the original knowledge, and also constantly filter and classify the outside information and convert it into their own thinking. In this process, a variety of non-intelligence factors are blended.

\section{Conclusion}

Through the discussion of this paper, it is known that mind mapping can significantly improve the initiative and interest of higher vocational students in learning if it is applied to the autonomous learning of higher vocational students. At the same time, mind mapping is also helpful for students to break the traditional mindset, make knowledge innovation and understand and absorb the overall significance of knowledge. As a result, they can effectively and systemically grasp the knowledge, the ability in analysis and understanding is improved to some extent, and a complete way of thinking and consciousness of cooperative learning can be cultivated. Due to the limitation of various factors, however, the application of mind mapping to the autonomous learning of higher vocational students must be further studied, and then its biggest advantage can be played.

\section{Acknowledgement}

Subject: Hebei Province Education Science Research "12th Five Year" plan topic "the thought chart in the vocational students" study independently study the application research "number 1414331

\section{References}

[1] Li GAO, Suhong MENG. The Application of Mind Mapping to Education and Teaching [J]. Journal of Chinese Modern Education Equipment, 2007 (6).

[2] Shui HE. Exploration on the Values of Mind Mapping in Teaching $[\mathrm{J}]$. China's Afterschool Education (Theory), 2007 (01).

[3] Guoqing ZHAO, Zhijian LU. Analysis on "Concept Map" And "Mind Map" [J]. China Audio-Visual Education, 2004 (08). 